\title{
CORRECTION
}

\section{Correction to: Evaluating the Impact and Benefits of Fluticasone Furoate/Vilanterol in Individuals with Asthma or COPD: A Mixed-Methods Analysis of Patient Experiences}

Henrik Svedsater $\cdot$ Helen A. Doll · Jake Macey $\cdot$ Gail Miles ·

Lisa Bradshaw $\cdot$ Magdalena Vanya

Published online: September 3, 2021

(c) Springer Healthcare Ltd., part of Springer Nature 2021

Correction to: Adv Ther (2018) 35:1378-1399

https://doi.org/10.1007/s12325-018-0760-7

There is an error in the DOI link of the original publication. The error has been resolved.

The original article can be found online at https://doi. org/10.1007/s12325-018-0760-7.

H. Svedsater $(\bowtie)$

Value Evidence and Outcomes, GSK, GSK House,

Brentford, Middlesex, UK

e-mail: henrik.x.svedsater@gsk.com

H. A. Doll $\cdot$ J. Macey

ICON, ICON Clinical Outcome Assessments,

Abingdon, UK

G. Miles

BreathingSpace, Rotherham, UK

L. Bradshaw

Centre for Workplace Health, Northern General

Hospital, Sheffield, UK

M. Vanya

ICON Plc, San Francisco, CA, USA 